\title{
Is Novel Corona Virus Truly a Trigger for Kawasaki Disease in Infants?- Reporting the First Asian Case
}

Bhaswati C Acharyya ( $\sim$ bacharyya21@gmail.com )

AMRI HOSPITALS https://orcid.org/0000-0001-5435-2114

Saumyabrata Acharyya

AMRI HOSPITALS

Dhritabrata Das

AMRI Hospitals

\section{Case Report}

Keywords: COVID 19 in infants; Kawasaki Disease; COVID19 \& Hyperinflammatory pathology

Posted Date: May 20th, 2020

DOI: https://doi.org/10.21203/rs.3.rs-29420/v1

License: (1) This work is licensed under a Creative Commons Attribution 4.0 International License.

Read Full License 


\section{Abstract}

SARSCov2 pandemic has hit the world this year with alarming consequences in most of the continents. There are relatively few reported cases of COVID-19 infection in children, compared to the total number of cases in the general population. Children are battling the infection more positively unless they have preexisting morbidity. Interestingly an inflammatory condition is being reported from western world in this COVID 19 era with increased risk of mortality. We report the first Asian infant with florid features of Kawasaki Disease who eventually tested positive for Novel Corona virus.

\section{Introduction}

The present pandemic of COVID 19 has threatened the world with extreme morbidity and mortality. The paediatric population was so far not affected as dreadfully as the elderly fraternity. Severe COVID-19 in children is rare. To date, the largest review of children with COVID-19 included 2143 children in China. Only $5.8 \%$ had severe disease (defined as hypoxia) and only $0 \cdot 6 \%$ children developed respiratory or multiorgan failure or acute respiratory distress syndrome (ARDS)(1). But recently, a new inflammatory pathology manifesting as Kawasaki Disease or Kawasaki like shock syndrome has been described in children above 4 years of age from the western world during this pandemic era. $(2,3)$. However, no such clinical scenario has been reported from the Asian (including Chinese) Paediatric population. Here we report a unique case presenting with fever and clinical manifestations of Kawasaki Disease eventually screening positive for COVID 19.

\section{Case Report}

A 4-month-old baby, born of non-consanguineous parents with uneventful antenatal and postnatal history; so far healthy and well grown, presented with high-grade fever for 4 days. Fever was spiking 6-8 hourly reaching $39^{\circ} \mathrm{C}$. He developed an erythematous macular rash over the trunk, palm and sole on $2^{\text {nd }}$ day. His birth-weight was $2.7 \mathrm{~kg}$ and presently was weighing $5.6 \mathrm{~kg}$. There was no symptomatic COVID 19 case in the family and the child was confined at home since the lockdown imposed in the country 38 days back. On admission the child was haemodynamically stable and was breastfeeding normally. He had red lips and red congested throat with small cervical lymphadenopathy. He was very cranky and irritable which elicited a suspicion of meningitis with or without sepsis. He did not have any cough or nasal congestion. On auscultation, his chest was clear and heart rate was 110 to 120/min and regular. He was maintaining a saturation of $97-98 \%$ in air. Initial investigations revealed a haemoglobin of $9.9 \mathrm{gm} / \mathrm{dL}$, total leucocyte count (TLC) of $14770 / \mathrm{mm} 3$ with $50 \%$ neutrophil, platelet count $4.25 \mathrm{lac} / \mu \mathrm{L}$ C Reactive protein (CRP) of $115.6 \mathrm{mg} / \mathrm{L}$ (Normal up to $9.9 \mathrm{mg} / \mathrm{L}$ ), normal liver enzymes with albumin $30 \mathrm{~g} / \mathrm{L}$ and globulin of $22 \mathrm{~g} / \mathrm{L}$. He had a normal chest X-ray. His nasopharyngeal swab was sent for COVID 19 RT-PCR and other viral PCR tests. The infant was started with broad spectrum antibiotics after sending blood and urine culture but fever continued to spike up to the third day of admission and he developed nonpurulent 
conjunctivitis with left subconjunctival haemorrhage. Repeat CRP showed a higher value of $178.2 \mathrm{mg} / \mathrm{L}$. With evolving clinical signs simulating Kawasaki Disease, an echocardiography was performed while awaiting the viral PCR report. His viral swab was negative for any virus or bacteria. Echocardiography showed normal left ventricular function, perivascular brightness and diffuse ectasia of coronary arteries with left middle coronary artery (LMCA) of $2.7 \mathrm{~mm}(\mathrm{z}$ score +2.6$)$ [Fig 1], left anterior descending artery of $2 \mathrm{~mm}$ (Zscore +2.9$)$ and proximal right coronary artery (RCA) of $2.4 \mathrm{~mm}$ (z score +3.6$)$ [Fig 2]. He was started with oral Aspirin $(80 \mathrm{mg} / \mathrm{kg} /$ day) and intravenous gamma globulin $(2 \mathrm{gm} / \mathrm{kg})$. He stayed stable clinically and did not need intensive care. Fever subsided after 24 hours of finishing gamma globulin and child became playful. Subsequently COVID 19 PCR showed a positive result and was shifted to a COVID designated hospital. All cultures were negative till 7days. Repeat blood test revealed a downward trend of CRP $(148 \mathrm{mg} / \mathrm{L})$. To date the baby is stable, afebrile, and is kept under observation in the Paediatric ward. Later his mother was found positive for SARS CoV2 as well.

\section{Discussion}

Children of all ages can acquire COVID-19, although they appear to be affected less commonly than adults $(1,4,5,6,7)$. However, compared to the numbers in adult series reported from Chinese, European and American populations Paediatric data is dismal. In a systematic literature review (from January 1 through March 18, 2020), children accounted for 1 to 5 percent of diagnosed COVID-19 cases (8). In USA, infants accounted for 15 percent of confirmed cases till $2^{\text {nd }}$ April. The proportion of all cases that have occurred in infants ( 0.27 percent) is less than the proportion of the United States population that is $<1$ year of age (6). The present infant with hyperinflammatory disease is the $1^{\text {st }}$ case with severe disease reported in this part of the globe without any immediate symptomatic contacts.

The most common symptoms in paediatric SARS CoV2 infection are fever and cough as described in different series from Chinese and American experience (4.6). This infant also presented with fever characterised by extreme irritability conspicuous by the absence of respiratory symptoms.

In the Chinese series, $5.8 \%$ of children had severe and critical disease(1) However, in the same series, among infants approximately 11 percent had severe or critical diseases.(1). The discussed infant was never critical throughout the period of hospitalisation though considering the inflammatory features associated with his disease it could have been critical.

There have been few reports of children with COVID-19 and clinical features that are similar to those of toxic shock syndrome and atypical Kawasaki disease (eg, abdominal pain, gastrointestinal symptoms, myocarditis) and laboratory findings associated with increased inflammation (eg, elevated CRP, erythrocyte sedimentation rate, and ferritin) (3). Royal College of Paediatric and Child Health(UK) published this new inflammatory entity as "Paediatric multisystem inflammatory syndrome temporarily associated with COVID 19" (9). Case definitions include persistent fever, inflammation (neutrophilia, elevated CRP, and lymphopenia) and evidence of single or multi-organ dysfunction (shock, cardiac, respiratory, renal, gastrointestinal, or neurological disorder). This may include children fulfilling full or 
partial criteria for Kawasaki disease. Other microbial causes which may give rise to these features should be excluded. The discussed case had markedly raised CRP without any neutrophilia or lymphopenia or organ dysfunction though fulfilled criteria for Kawasaki Disease.

Jones et al. in this pandemic period, published the first case of a 6-month-old female admitted and diagnosed with classic Kawasaki disease (KD), who tested positive for COVID 19. Our case was very similar to theirs but the 6-month-old had most of the clinical features of KD without any echocardiographic findings though the girl had persistent tachycardia (200/min). In contrast the present infant had diffuse coronary arterial ectasia, perivascular brightness with normal left ventricular function despite having normal heart rate. Like our case, Jones et al also treated the infant with IV gamma globulin and high dose Aspirin which gave dramatic relief as happens usually in typical KD.

A recent literature search revealed a case series of 8 previously healthy children above 4 years of age from southeast England admitted in Paediatric Intensive care with a hyperinflammatory shock like atypical KD, Kawasaki Shock Syndrome or Toxic Shock Syndrome. One child died after a massive cerebral infarction despite optimal management. All of them have common clinical features with persistent fever $\left(38-40^{\circ} \mathrm{C}\right)$, variable rash, conjunctivitis, peripheral oedema, and generalised pain with significant gastrointestinal symptoms. All progressed to warm, vasogenic shock, refractory to volume resuscitation and eventually requiring noradrenaline and milrinone for haemodynamic support. They had minimal or no respiratory symptoms. Only three of them had positive COVID 19 results (3). Our case, the other KD case, and these children most likely had similar pathogenesis with varied severity but need further research to define it. How much SARS CoV 2 is responsible for this inflammatory pathology and through which pathway it is activating the immune phenomena are still not clear. Cytokine storm and shock suggesting hyper inflammation had been described in adult series from China but particular Kawasaki Disease like presentation or Kawasaki Shock Syndrome had not been described $(10,11)$. Very recently one such case from Southern part of India has been reported in an eight year oid child(12). Ferritin, troponin and IL6 levels would be the right parameters to monitor in this infant which are not available while submitting this report.

Aetiology of KD is still not known but a viral association had been suspected in many studies. Infection by a ubiquitous agent(? RNA virus) had been suggested as the initiating factor in the pathogenetic model by Rowley et al (13). Whether Coronavirus 19 is acting as that agent in these patients causing vasculitis is still to be proved. More research will be needed to unveil this hyperinflammatory phenomenon in the midst of this pandemic.

India is still in the early stage of this pandemic and had not yet experienced many severe cases occurring in children. To the best of our knowledge, this 4-month-old child represents the first case, among the Asian Paediatric population of COVID 19 presenting as full blown Kawasaki Disease. This novel case is an eye-opener for our awareness of the hyperinflammatory manifestations caused by the novel Coronavirus in Indian vis- a-vis Asian children. 


\section{Abbreviations}

KD Kawasaki Disease

COVID19 Corona viral Disease 2019

RT-PCR Reverse Transcriptase Polymerase Chain Reactions

SARS CoV 2 Severe Acute Respiratory syndrome Corovavirus 2

IL6 Interleukin 6

\section{Declarations}

Conflict of Interest: None

Permissions have been obtained from the parents about the publication of the case by Dr Saumyabrata Acharyya

Author Contributions:

Bhaswati C Acharyya - Prepared the manuscript

Saumyabrata Acharyya - Managed the case, supplied the clinical details corrected spelling and grammar

Dhritobrata Das - Contributed the echocardiographic pictures and corrected the cardiac findings portion of the text

\section{References}

1. Dong Y, Mo X, Hu Y, Qi X, Jiang F, Jiang Z, Tong S. Epidemiology of COVID-19 Among Children in China. 2020;145(6)

2. Jones VG, Mills M, Suarez D, et al. COVID-19 and Kawasaki disease: novel virus and novel case. Hosp Pediatr.2020

3. Riphagen S, Gomez X, Gonzalez-Martinez C, Wilkinson N, Theocharis P. Hyperinflammatory shock in children during COVID-19 pandemic. Lancet 2020 (Online May 6)

4. Lu X, Zhang L, Du H, Zhang J, Li YY, Qu J, Zhang W, Wang Y, Bao S, Li Y, Wu C, Liu H, Liu D, Shao J, Peng X, Yang Y, Liu Z, Xiang Y, Zhang F, Silva RM, Pinkerton KE, Shen K, Xiao H, Xu S, Wong GWK, Chinese Pediatric Novel Coronavirus Study Team. SARS-CoV-2 Infection in Children. N Engl J Med. 2020;382

5. Wei M, Yuan J, Liu Y, Fu T, Yu X, Zhang ZJ. Novel Coronavirus Infection in Hospitalized Infants Under 1 Year of Age in China [published online ahead of print, 2020 Feb 14]. JAMA. 2020;323(13):13131314. 
6. CDC COVID-19 Response Team. Coronavirus Disease 2019 in Children - United States, February 12April 2, 2020. MMWR Morb Mortal Wkly Rep. 2020;69(14):422-426.

7. Zimmermann P, Curtis N. Coronavirus Infections in Children Including COVID-19: An Overview of the Epidemiology, Clinical Features, Diagnosis, Treatment and Prevention Options in Children. Pediatr Infect Dis J. 2020; 39(5):355-368.

8. Ludvigsson JF. Systematic review of COVID-19 in children shows milder cases and a better prognosis than adults. Acta Paediatr. 2020;109(6):1088-1095

9. Royal College of Paediatrics and Child Health. COVID-19 guidance for pediatric services

10. Ruan Q, Yang K, Wang W, Jiang L, Song J. Clinical predictors of mortality due to COVID-19 based on an analysis of data of 150 patients from Wuhan, China. Intensive Care Med 2020; published online March 3

11. Mehta P, McAuley DF, Brown M, Sanchez E, Tattersall R, Manson JJ. COVID-19: consider cytokine storm syndromes and immunosuppression.Lancet 2020;395:1033-1034

12. Balasubramaniani S, Magendran TM, Ramachandran B, Ramanan AV. Hyper-inflammatory Syndrome in a Child With COVID-19 Treated Successfully With Intravenous Immunoglobulin and Tocilizumab. Indian Pediatr.2020; May(online)

13. Rowley AH, Shulman ST. The Epidemiology and Pathogenesis of Kawasaki Disease. Frontiers in pediatrics. 2018;6:374.

\section{Figures}

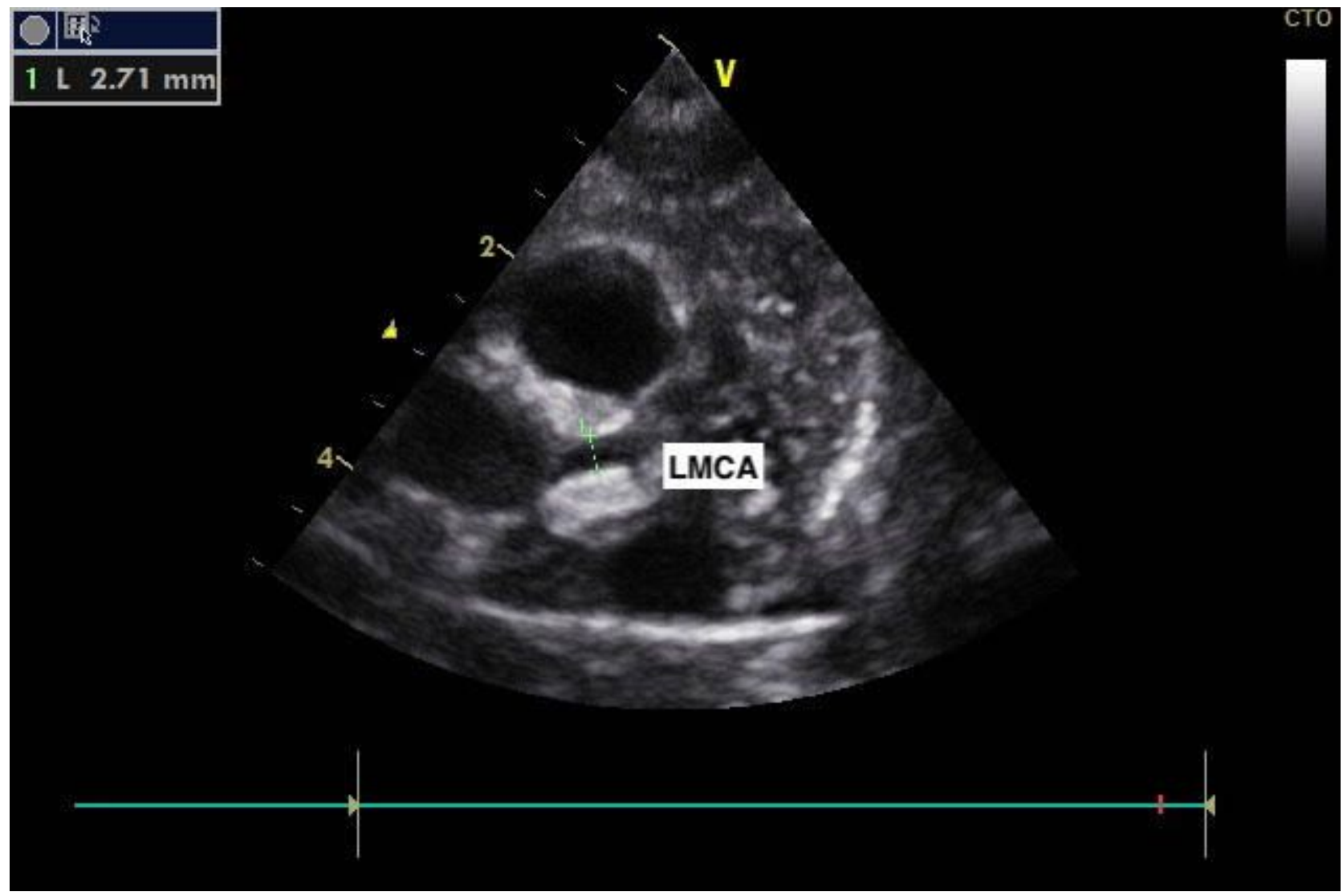


Figure 1

Ectasia of LMCA

$\frac{\mathrm{O} \mathrm{H}_{8}}{1 \mathrm{~L} 2.39 \mathrm{~mm}}$

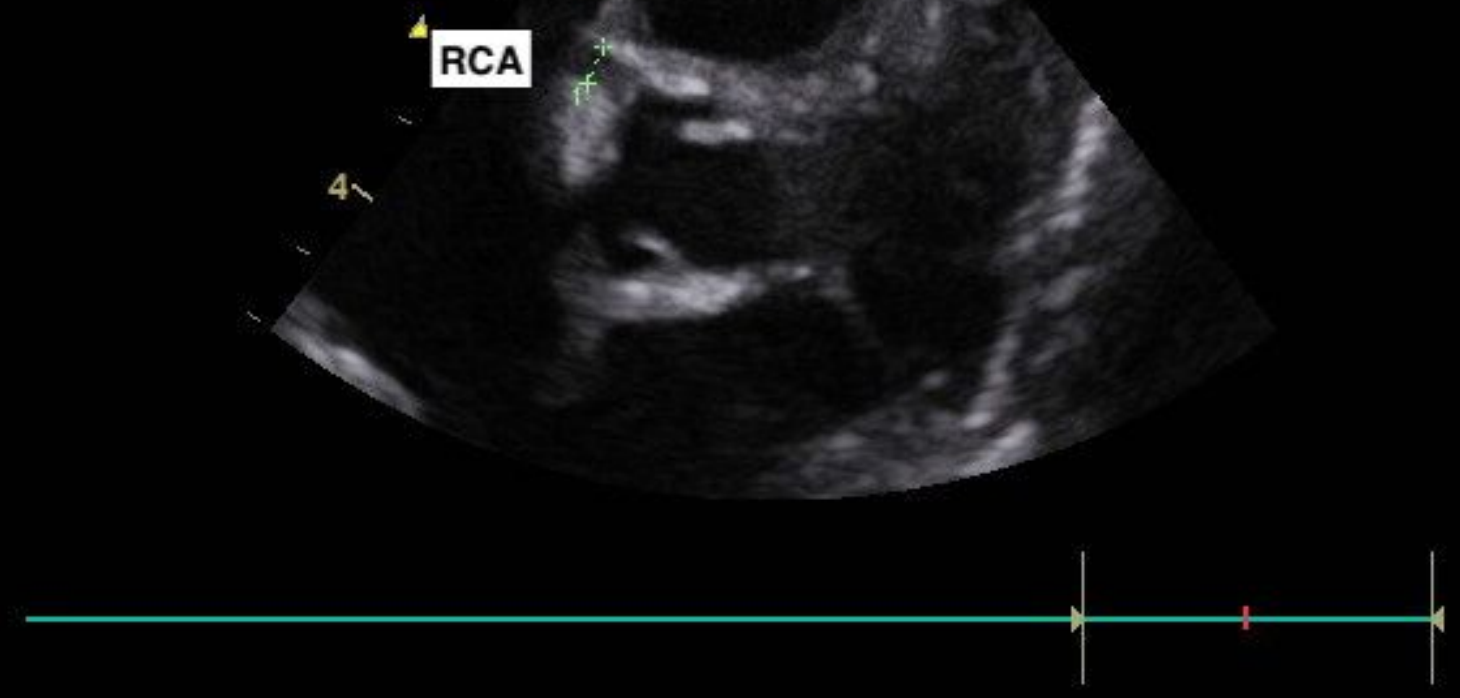

Figure 2

Ectasia of RCA 